\title{
The Machinic Temporality of Metadata
}

\section{Claudio Celis}

\author{
Cardiff University, Cardiff, UK, claudiocelis@yahoo.com
}

\begin{abstract}
In 1990 Deleuze introduced the hypothesis that disciplinary societies are gradually being replaced by a new logic of power: control. Accordingly, Matteo Pasquinelli has recently argued that we are moving towards societies of metadata, which correspond to a new stage of what Deleuze called control societies. Societies of metadata are characterised for the central role that meta-information acquires both as a source of surplus value and as an apparatus of social control. The aim of this article is to develop Pasquinelli's thesis by examining the temporal scope of these emerging societies of metadata. In particular, this article employs Guattari's distinction between human and machinic times. Through these two concepts, this article attempts to show how societies of metadata combine the two poles of capitalist power formations as identified by Deleuze and Guattari, i.e. social subjection and machinic enslavement. It begins by presenting the notion of metadata in order to identify some of the defining traits of contemporary capitalism. It then examines Berardi's account of the temporality of the attention economy from the perspective of the asymmetric relation between cyber-time and human time. The third section challenges Berardi's definition of the temporality of the attention economy by using Guattari's notions of human and machinic times. Parts four and five fall back upon Deleuze and Guattari's notions of machinic surplus labour and machinic enslavement, respectively. The concluding section tries to show that machinic and human times constitute two poles of contemporary power formations that articulate the temporal dimension of societies of metadata.
\end{abstract}

Keywords: Marx, Control Societies, Deleuze, Guattari, Machinic Time, Big Data, Attention Economy, Cognitive Capitalism, Metadata.

Acknowledgement: This paper is part of a research project funded by CONICYT, Chile.

\section{Introduction}

In a recent article, Matteo Pasquinelli introduces the concept of societies of metadata in order to define the "current evolution of that society of control that was already pictured by Deleuze" $(2014,3)$. In general terms, societies of metadata organize flows of information using algorithms and databases in order to accelerate the production and accumulation of machinic surplus value (Pasquinelli 2014, 15-6). The biggest merit of Pasquinelli's text is to highlight how the connection between Italian Operaismo and Deleuze and Guattari's notion of the machinic allows a more informed understanding of the economic and political dimensions of contemporary capitalism. The aim of this article is to develop Pasquinelli's analysis by examining the temporal scope of these emerging societies of metadata. Whereas labour in industrial capitalism could be explained through the complicity between clock-time and disciplinary institutions, post-industrial capitalism demands a new understanding of the relation between labour, time, and power. This paper contends that Deleuze and Guattari's reinterpretation of Marx provides a useful toolbox from where to advance a critique of societies of metadata. In particular, Felix Guattari's concept of machinic time (2009) makes it possible to suggest that there is an internal relation between the current phenomenon of metadata, the transformations of labour put forth by post-Fordism, and the new technologies of power that characterise control societies.

The present article is divided in five sections. First, it presents the notions of attention economy and big data in order to identify how attention and information have become active elements not only for the production of surplus value but also as new mechanisms of social control. Second, it examines Berardi's $(2009 ; 2011)$ account of the temporality of the attention economy from the perspective of the asymmetric relation between cyber-time and hu- 
man time. The third section challenges Berardi's definition of the temporality of the attention economy by using Guattari's (2009) notions of human and machinic times. According to Guattari, human and machinic times refer not to an ahistorical definition of temporality, but to two concrete mechanisms through which capital attains to subsume human activity. To explain this, parts four and five fall back upon Deleuze and Guattari's notions of machinic surplus labour and machinic enslavement, respectively. The concluding section tries to show that machinic and human times constitute two poles of contemporary power formations that articulate the temporal dimension of societies of metadata.

\section{From the Attention Economy to Societies of Metadata}

The current debate about the concept of Big Data (Manovich 2012; Davenport et al. 2012; Boyd and Crawford 2012; Pasquinelli 2014) can be read as an updated version of an older discussion on the so-called attention economy. In this regard, referring back to the notion of the attention economy can help develop an understanding of some of the main characteristics of what Pasquinelli calls societies of metadata $(2014,15-6)$.

The attention economy is a concept forged within the field of political economy in order to explain the growing value of attention in a world rich in information (Simon 1969). The fact that information acquires such a crucial role for the productive process implies that the attention necessary to process this information increasingly becomes a scarce resource. In this sense, the attention economy is a phenomenon that responds directly to the transformations taking place within the productive arena, which involve the passage from industrial massproduction to so-called knowledge capitalism (Negri and Hardt 1999, 79). Moreover, with the spread of mass media and digital technologies, attention itself becomes a source of information that is fed back directly into the productive process, easing the communication link between the spheres of consumption and production, and hence accelerating the extraction and realisation of surplus value.

The concept of attention economy has become an important object of critical analysis in recent years (Beller 2006; Marazzi 2008; Andrejevic 2012; Crogan and Kinsley 2012). The spread of the Internet and global mass media has motivated a large number of critical responses that try to show how the attention economy becomes a new form of exploitation. Mark Andrejevic (2012), for example, uses Tiziana Terranova's concept of "free labour" (2004) to argue that the attention economy constitutes a new form of estrangement and exploitation since human attention becomes a specific activity that generates value but for which is unpaid. In this sense, the Internet becomes a concrete mechanism through which the economic value generated by the users' time online is appropriated and monetised, expanding the production of surplus value from the factory to the whole of society.

With the development of the so-called Web 2.0 and the emergence of more advance algorithms, however, the concept of attention economy has evolved into that of big (or deep) data (Davenport et al. 2012, 22). The main difference between the attention economy and big data is that while the former uses human attention as a source of information about consumers' habits and preferences, the latter accumulates this information in order to extract from it metadata (or "information about information") and hence unveil the "collective and political nature that is intrinsic to all information" (Pasquinelli 2014, 14). In this sense, as Manovich $(2012,460)$ notes, the difference between the attention economy and metadata is not a difference of degree (big data meaning more data), but a qualitative difference made possible by the harvesting of information about information. Nevertheless, it is important to mention that big data still relies on human attention as one of the main sources of the information it harvests and processes. This becomes clear in the description that Matteo Pasquinelli provides of the current stage of metadata:

The accumulation of information and extraction of metadata performed every day by the global digital infrastructure is massive: take, for instance, search engines like Google, social networks like Facebook and Twitter, online stores like Amazon and any global logistic service. The new global scale of metadata extraction has started only recently to disclose a new perspective on the governance of the means of production: this shift has been fa- 
mously acknowledged by recent business literature as 'big data' or the 'industrial revolution of data'. (Pasquinelli 2014, 15)

Furthermore, Pasquinelli contends that this new perspective "on the governance of the means of production" inaugurates a new stage of capitalist power formations $(2014,15)$. He refers to it with the notion of societies of metadata, which corresponds to the current phase of what Deleuze defined as societies of control (Pasquinelli 2014; Deleuze 1995). The three main characteristics of societies of metadata, as sketched by Pasquinelli, are: 1) metadata becomes the "measure of the value of social relations"; 2) metadata is used to improve "the design of machines and machinic intelligence' and hence to generate "machinic surplus value"; and 3) metadata becomes a new mechanism of social control, or "dataveillance" (Pasquinelli 2014, 15-6).

The aim of this article is to develop Pasquinelli's hypothesis by focusing on the temporal scope of societies of metadata. What happens to temporal experience when attention and information become new economic territories? To what degree are these temporal transformations connected to broader issues such as the role of labour-time in post-Fordism and that of machinic enslavement in control societies? How does the passage from Fordism to postFordism challenge the notion of labour time that informs Marx's labour theory of value?

\section{Cyber-Time (or the inhuman time of information)}

According to Franco Berardi (2011), the cognitive turn that characterises post-Fordism (which places knowledge and information at the heart of the productive process) turns labour time into an obsolete category to act as the measure of value. With the technological mutations introduced by post-Fordism:

something new happens in the relationship between time, work, and value [...] work ceases to be the strong, muscular work of industrial production, and begins producing signs-products that are essentially semiotic. In order to establish the average time needed to produce a glass, one simply needs to understand the material labour involved in converting sand into glass, and so forth. But try to decide how much time is needed to produce an idea, a project, a style, a creation, and you find that the production process becomes semiotic, with the relationship between time, work, and value suddenly evaporating, melting into air. (Berardi 2011)

Berardi also notes that Marx himself was the first to pose the question of the historical limits of labour time. In the Grundrisse, Marx defines capitalism as "the moving contradiction" which employs technology to reduce necessary labour time while at the same time posing labour time as "sole measure and source of wealth" $(1973,706)$. In order to counteract the tendency to crisis inherent in this contradiction, capitalism is forced to reduce constantly the amount of necessary labour time and increase the amount of relative surplus value. This tendency propels capitalism into a continual process of acceleration. In Berardi's words, "when Marx speaks of relative surplus value he is speaking about acceleration: if you want a growth in productivity - which is also a growth in surplus value-you need to accelerate work time" (2011). With the historical transition to post-Fordism and the implementation of automation and information technologies in the productive process, the tendency towards acceleration and speed proper of capitalism enters a new phase that renders labour-time an obsolete measure of value (Berardi 2011). ${ }^{1}$

\footnotetext{
${ }^{1}$ There have been several theoretical responses to the new phase of acceleration characteristic of post-Fordism (or late capitalism): David Harvey defines this stage through the notion of a "postmodern time-space compression" in which time "annihilates" space $(1989,299)$; Paul Virilio $(1991 ; 1995 ; 2006)$ analyses the relation between speed, capitalism and politics in a world in which real-time gradually replaces the physical limits of space; Manuel Castells proposes the notions of flexible and network times as an alternative to the linear time of industrial capitalism (2010, 467-8); Jonathan Crary argues that digital technologies are creating a "24/7" time where no aspect of life escapes the economic cycles of capitalism, thus causing a 'brutal discrepancy between the temporal operation of deregulated markets and the intrinsic physical limitations of the humans required to conform these demands' (2013 15); finally, Cristian Marazzi suggests that together with the crisis of industrial capitalism comes a crisis of
} 
In the case of the attention economy, the logic of acceleration can be employed to explain the growing discrepancy between human attention-time and the inhuman time of the flows of information. ${ }^{2}$ Franco Berardi argues that when labour becomes cognitive, acceleration comes to depend less on manual work and more on the speed of the info-sphere (2011). The problem, he notes, is that since the brain "functions in time, and needs time in order to give attention and understanding [...] attention cannot be infinitely accelerated" (2011). Therefore, Berardi concludes, in the attention economy speed and acceleration are "linked to the relation between the amount of semiotic goods being produced and the amount of attentive time being disposed of" (2011). From this perspective, the temporality of the attention economy appears as the result of an asymmetrical relation between the limited temporality of the subject (or user) and the relatively unlimited temporality of the flows of information (or cybertime). Berardi sums it up in the following way:

\begin{abstract}
[the essential problem with the attention economy is that] the rhythms of the technological mutation are a lot faster than those of mental mutation. Hence the expansion of cyberspace is incommensurably faster than the human brain's capacity to expand and adapt. We can increase the length of time an organism is exposed to information, but experience can't be intensified beyond a certain limit. Acceleration provokes an impoverishment of experience, given that we are exposed to a growing mass of stimuli that we can't digest in the intensive modes of enjoyment and knowledge $(2009,89)$.
\end{abstract}

The problem with this understanding of the temporality of the attention economy is that it reproduces an obsolete opposition between the temporality of living labour and that of dead, fixed capital. Put differently, by defining the temporality of the attention economy through the discrepancy between a human, subjective time and the cyber-time of the info-sphere, Berardi (2009; 2011) repeats Marx's distinction between living labour time and dead technical time, and fails to acknowledge the obsolescence of Marx's theory of value. Furthermore, Berardi universalises abstract human time as the sole source and measure of value and poses human time as an external, ahistorical standpoint from where to develop a critique of the attention economy. Hence, Berardi replicates the methodological error that is committed by traditional Marxism: he universalises a given notion of time and thereby renders it a transcendental character of the human constitution.

As Moishe Postone (1993) suggests, labour should not be understood as a transhistorical category that grounds all forms of social constitution. Instead, labour should be conceived of as a strictly capitalist category (i.e. human activity measured in terms of abstract value). For Postone $(1993,7)$, it is a methodological error to presuppose a universal notion of labour as an external standpoint from where to develop a critique of capitalism. Instead, he calls for a critique of the notion of labour itself. This methodological error can be found in Berardi's $(2009 ; 2011)$ account of the temporality of the attention economy: Berardi opposes a human-time to a dehumanising cyber-time and uses the former as an ahistorical criterion from where to criticize the rapid acceleration of the latter. Alternatively, Guattari's (2009) notion of machinic time allows developing a critical analysis of the temporality of societies of metadata that acknowledges the historical transformations put forth by post-Fordism and which does not universalise a given notion of human time.

\footnotetext{
"Newtonian time", a crisis "of industrial time as homogeneous, abstract, chronometric, computable objectifiable time, external to human beings and to things" $(2008,51)$.

${ }^{2}$ Since its original formulation by Herbert A. Simon (1969), the question of time as the measure of the value of attention has been a central concern for both the apologists and critics of the attention economy. Simon suggests that to efficiently allocate attention, "ways must be found to measure the quantities of the scarce resource" (1969, 7). A way of doing this, he suggests, is measuring the attention-time necessary for the consumption of a given message: "scarcity of attention in an information-rich world will be measured by the time, in minutes or in hours, say, of a human executive" $(1969,8)$. For Simon, this is possible because human attention is essentially a serial activity, i.e. if we attend to one thing, we cannot, "simultaneously, attend to another" $(1969,8)$. In this respect,
} 


\section{Human and machinic time}

According to Felix Guattari, in contemporary societies 'human time is increasingly replaced by machinic time' $(2009,249)$. Unlike Berardi's account of cyber-time, Guattari's distinction between human and machinic times does not attempt to naturalise a specific form of time (human time) that becomes alienated by technology in the form of machinic time. On the contrary, for Guattari, human and machinic time refer to two dispositions of labour under capitalist conditions of production. In other words, human and machinic time define two mechanisms through which capitalism produces and accumulates surplus value. This understanding of human time and machinic time as two temporal manifestations of capitalism is crucial to avoid any metaphysical critique of the temporality of societies of metadata. Furthermore, it makes it possible to connect the temporality of metadata to broader transformations of labour and power in post-Fordist capitalism.

In the historical age of capitalist social order that had not yet undergone the process of industrial revolution (what Marx has called the stage of formal subsumption of labour under capital), the central aim of a tool (or simple machine) was to reduce the amount of necessary labour-time required for the production of a specific commodity and hence to increase the amount of (absolute) surplus value appropriated by the capitalist. In this stage, human labour appeared as the conductor of the tool, which the labourer "animated and made into his organ with his skill and strength, and whose handling therefore depended on his virtuosity" (Marx $1973,693)$. With the advent of the industrial revolution and the subsequent mechanization of the labour process (the stage of real subsumption), however, human activity becomes subsumed under the machine, which appears now as its "conductor". Marx writes that in modern industry:

[t]he worker's activity, reduced to a mere abstraction of activity, is determined and regu-
lated on all sides by the movement of the machinery, and not the opposite. The science
which compels the inanimate limbs of the machinery, by their construction, to act pur-
posefully, as an automaton, does not exist in the worker's consciousness, but rather acts
upon him through the machine as an alien power, as the power of the machine itself [...]
The production process has ceased to be a labour process in the sense of a process
dominated by labour as its governing unity. Labour appears, rather, merely as a con-
scious organ, scattered among the individual living workers at numerous points of the
mechanical system; subsumed under the total process of the machinery itself, as itself
only a link of the system, whose unity exists not in the living workers, but rather in the liv-
ing (active) machinery, which confront his individual, insignificant doings as a mighty or-
ganism. $(1973,693)$

In this context, technical progress (objectified as fixed capital) radically reduces necessary labour-time, increasing the amount of (relative) surplus value appropriated by capital. Furthermore, human labour becomes an appendage of machinic labour. Nevertheless, as Marx also notes, despite this hierarchic inversion between human and machinic labour, human labour-time continues to be posed as the sole measure of value $(1973,706)$. As mentioned above, Marx argues that capital's main contradiction is that it 'presses to reduce labour time to a minimum, while it posits labour time [...] as the sole measure and source of wealth' (1973, 706). Marx writes:

On the one side, [capital] calls to life all the powers of science and of nature, as of social combination and of social intercourse, in order to make the creation of wealth independent (relatively) of the labour time employed on it. On the other side, it wants to use labour time as the measuring rod for the giant social forces thereby created, and to confine them within the limits required to maintain the already created value as value. $(1973,706)$

For Guattari (2009), the contradiction between human time and machinic labour explains the crisis of industrial capitalism and the consequent emergence of post-industrialism. Following Marx, Guattari claims that despite being grounded on machinery, industrial capitalism still relies on human abstract time as a general equivalent of value $(2009,249)$. Because of its 
dependency on human time, industrial capitalism continuously revolutionises the means of production in order to reduce the amount of necessary labour-time and hence increase surplus value. The consequence of this continuous transformation of the productive process is the constant increase of society's general productive powers (Marx 1973, 705). The accumulation of these productive powers leads to a post-industrial revolution in which knowledge, science and information become crucial to the production of surplus value. In this context, Guattari suggests, value can no longer be legitimately grounded strictly on human labour time $(2009,249)$. It is important to note, however, that the transition from industrial to postindustrial societies does not mean that human time ceases to be exploited. Guattari only suggests that human time can no longer be used as a general equivalent of value. At the same time, he argues, the exploitation of labour becomes subsumed under a more complex productive arrangement in which "the administration of the capital of knowledge, the degree of participation in the organization of labour, the corporate spirit, and collective discipline, etc.", become determining elements in the production of surplus value $(2009,247)$. The concept of machinic time, then, is employed in order to define the temporality of these new productive arrangements that ground the new forms of machinic surplus value characteristic of post-industrial societies (Guattari 2009, 249).

Guattari's concept of machinic time paves the way for connecting the analysis of the temporality of societies of metadata to the broader transformation put forth by post-Fordism. As mentioned above, Pasquinelli argues that in contemporary societies metadata becomes the measure of the value of social relations $(2014,15)$. In this context, human time can no longer be posed as the general equivalent of surplus value. Instead, human time becomes integrated in a broader machine aimed at harvesting meta-information capable of accelerating the extraction and realisation of machinic surplus value. Machinic time is another way of defining the "measure of the value of social relations" in a context in which meta-information has replaced direct labour time as the main source of surplus value.

\section{Machinic surplus labour and machinic surplus value}

In order to develop the concept of machinic time, it is useful to refer to Deleuze and Guattari's notions of machinic surplus labour and machinic surplus value. In chapter fourteen of $A$ Thousand Plateaus, Deleuze and Guattari oppose the concepts of the smooth and the striated to explain two forms in which desire can be spatially organized $(2004,524)$. In general terms, these concepts refer to two forms of distributing movement within a given space: smooth (or nomad) space defines movement freed from any fixed or hierarchic trajectory, whereas striated (or sedentary) space structures and organizes movement according to stable points which delimit its range and extension. Put differently, smooth space tends to absolute movement in which variation is intensive, while striated space organizes movement in a way that variation can only manifest itself extensively.

In order to illustrate the difference between smooth and striated spaces, Deleuze and Guattari distinguish labour from free action: while the latter belongs to the domain of smooth space, the former can be seen as a result of striated space $(2004,541)$. More specifically, Deleuze and Guattari contend that it is only with the emergence of the State apparatus (that is, the institutional organization of striated space) that free action is systematically transformed into labour $(2004,541)$. This is so mainly for two reasons:

first, because labour appears only with the constitution of a surplus, there is no labour that is not devoted to stockpiling; in fact, labour (in the strict sense) begins only with what is called surplus labour. Second, labour performs a generalized operation of striaton of space-time, a subjection of free action, a nullification of smooth spaces. $(2004,541)$

As mentioned above, Postone (1993) contends that labour should not be understood as a human essence, but as a strictly capitalist category according to which human activity is subsumed under the logic of value (which entails both abstraction and measurability). In this sense, it can be said that labour constitutes a reterritorialization of human activity: labour demands a striated space-time that functions as its abstract measure. Furthermore, by sub- 
suming labour to the striated category of value, the State apparatus measures labour in relation to the amount of surplus that it does or does not produce. In other words, the State is constantly measuring the value of living labour against that of dead, accumulated labour.

With the development of technology, however, labour becomes "less and less distinguishable" from its surplus $(2004,542)$. This is so because technology (which is itself surplus labour accumulated as fixed capital) begins to gradually replace portions of labour within the valorisation process of capital. Furthermore, Deleuze and Guattari ask, "how could one possibly distinguish between the time necessary for reproduction and 'extorted' time, when they are no longer separated in time?" (2004. 542) For Deleuze and Guattari, the merging of labour and surplus labour put forth by the development of the productive forces does not "contradict the Marxist theory of surplus value" $(2004,542)$. On the contrary, the authors contend, Marx was the first one to acknowledge that with the development of the productive powers, "surplus value ceases to be localizable" $(2004,542)$. In this sense, Marx's "fundamental contribution" was to suggest that with the development of capitalism, "machines would themselves become productive of surplus value" and that this would in turn "challenge the distinction between variable and constant capital" $(2004,542)$. Deleuze and Guattari suggest that in post-industrial capitalism "it remains true that all labour involves surplus labour; but surplus labour no longer requires labour" $(2004,542)$. This means that post-industrial capitalism:

operates less and less by the striation of space-time corresponding to the physicosocial concept of work. Rather, it is as though human alienation through surplus labour were replaced by a generalized 'machinic enslavement', such that one may furnish surplus value without doing any work. $(2004,542-543)$

The physicosocial notion of labour (which informed classical political economy as well as Marx's labour theory of value) consists of the reterritorialization of human activity under a striated space-time (abstract labour time). ${ }^{3}$ In this sense, it can be argued that what Guattari (2009) calls 'human time' refers mainly to the abstract equivalent that works as the universal measure of the physicosocial notion of labour. In post-industrial societies, however, the application of information technologies in the productive process unveils a cognitive and immaterial dimension of human activity that demands a new conceptualisation of labour, time and surplus value. In this new productive context, surplus value is no longer produced only by reterritorializing human activity under a striated space-time, but by integrating cybernetic machines together with the cognitive dimension of labour. This integration produces what Deleuze and Guattari call machinic surplus labour, that is, a specific surplus of productive energy that does not necessarily involve labour (understood as the striated expenditure of human energy measured in terms of abstract time) or labour time, but which nonetheless produces machinic surplus value.

To illustrate this, Deleuze and Guattari refer to the act of watching television $(2004,543)$. Television viewers, they argue, can generate machinic surplus labour (which can then be monetized by television networks) without having to perform any work in the physicosocial sense of the term (i.e. as activity measured in terms of an abstract space-time striation). Deleuze and Guattari suggest that in post-industrial societies,

not only does the user as such tend to become an employee, but capitalism operates less on a quantity of labour than by a complex qualitative process bringing into play modes of transportation, urban models, the media, the entertainment industries, ways of perceiving and feeling-every semiotic system (ATP, 543).

\footnotetext{
${ }^{3}$ Deleuze and Guattari suggest that during the nineteenth century, "a twofold elaboration was undertaken: of a physicoscientific concept of work (weight-height, force-displacement), and of a socioeconomic concept of labour power or abstract labour (a homogeneous abstract quantity applicable to all work, and susceptible to multiplication and division" $(2004,540)$. In this sense, "there was a profound link between physics and sociology: society furnished an economic standard of measure for work, and physics a 'mechanical currency' for it. The wage regime had as its correlate a mechanics of force" $(2004,540-1)$.
} 
In similar fashion, it can be said that metadata operates as a concrete mechanism that transforms human attention into a source of machinic surplus labour. This means that societies of metadata do not subsume human activity under abstract-time, but it integrates the cognitive dimension of labour together with the productive forces unleashed by technological transformation. In this sense, the traditional categories of labour and labour time appear as insufficient to understand the production of surplus value. Furthermore, the concept of machinic time unveils the historical limits of the physicosocial definition of labour that informs Marx's understanding of the organic composition of capital which places living labour on the one side and machines on the other. Put differently, in post-industrial capitalism the concepts of constant and variable capital become an obsolete framework to explain the relation between labour, value and technology. For Deleuze and Guattari, these notions need to be replaced by an understanding of capitalism that takes into account the distinction between smooth and striated spaces:

The present-day accelerated forms of the circulation of capital are making the distinctions between constant and variable capital, and even fixed and circulating capital, increasingly relative; the essential thing is instead the distinction between striated capital and smooth capital, and the way in which the former gives rise to the latter through complexes that cut across territories and States. $(2004,543)$

However, Deleuze and Guattari note that contemporary capitalism does not simply replace labour as reterritorialized human activity with deterritorialized machinic surplus value. This means that human time is not replaced completely by machinic time. Instead, post-industrial capitalism articulates machinic and human time as two aspects of contemporary power formations: on the one hand, the striated space-time definition of labour "relates primarily to the state pole of capitalism, in other words, to the role of the modern State apparatuses in the organization of capital" $(2004,543)$; on the other hand, "a new smooth space is produced in which capital reaches its 'absolute' speed, based on machinic components rather than the human component of labour" $(2004,543)$.

To better understand how machinic and human times relate to each other in the specific context of societies of metadata let us turn to Deleuze and Guattari's concepts of machinic enslavement and social subjection. This will frame the question regarding the temporality of societies of metadata in the broader problematic of power.

\section{Machinic enslavement and social subjection}

In A Thousand Plateaus, Deleuze and Guattari argue that there are two general forms through which the state apparatus enforces power: machinic enslavement and social subjection. In machinic enslavement, they explain, humans become pieces of a larger machine "under the control of a higher unity" $(2004,504)$. To illustrate this, Deleuze and Guattari refer to Lewis Mumford's example of the mega-machine necessary to build the pyramids in ancient Egypt (2004, 504). In this enterprise, each slave became a human machine who transmitted energy to larger mechanism $(2004,505)$. In opposition to machinic enslavement, social subjection operates by rendering humans as the higher unity that coordinates production. In social subjection, humans relate externally to other machines, which they operate as subjects, users, or workers. In machinic enslavement a human is "enslaved by the machine', while in social subjection he or she is "subjected to the machine" $(2004,504)$.

Accordingly, in the 1980 essay referred to above, Guattari writes: "machinic enslavement does not coincide with social subjugation" $(2009,263)$. The latter, Guattari explains, involves "full-fledged persons, easily manipulated subjective representations", whereas:

[m]achinic enslavement combines infrapersonal and infrasocial elements, because of a molecular economy of desire more difficult to 'contain' within stratified social relations. Directly involving perceptive functions, affects, unconscious behaviours, capitalism takes 
possession of labour-power and desire, which extends far beyond that of the working class, sociologically speaking. $(2009,263)^{4}$

It is useful to point out that for Deleuze and Guattari, the term machine does not simply refer to what we commonly define as "technical machines". In fact, when we use or put to work a technical machine we are not speaking of machinic enslavement, but rather of social subjection, since we operate the machine as "subjects" or "users" (i.e. we as subjects are the higher unity guiding the machine). In this regard, Deleuze and Guattari define capitalism as a "worldwide enterprise of subjectification", that is, as the "point of subjectification that constitutes all human beings as subjects" $(2004,505)$.

With the passage from industrial to post-industrial society, however, capitalism pushes to restore, "in new and now technical forms, an entire system of machinic enslavement" (Deleuze and Guattari 2004, 505). With the introduction of automation and cybernetic machines 'the work regime changes' and 'surplus value becomes machinic' (Deleuze and Guattari 2004, 506). For this reason, Deleuze and Guattari state that, if "a small amount of subjectification took us away from machinic enslavement", then "a large amount brings us back to it" $(2004,506)$.

From this perspective, the passage from Fordism to post-Fordism can be interpreted as a restoration of new forms of machinic enslavement. Furthermore, this transformation of the logic of power seems to anticipate the central thesis of Deleuze's essay on control. ${ }^{5}$ However, Deleuze and Guattari quickly add that social subjection and machinic enslavement should not be conceived as successive stages, but rather as two coexistent poles of capitalist power formations that "constantly reinforce and nourish each other" $(2004,506)$. Deleuze and Guattari give the example of television in order to show how these two poles can coexist in one and the same object:

One is subjected to TV insofar as one uses and consumes it [...] ('you, dear television viewers, who make TV what it is...'); the technical machine is the medium between two subjects. But one is enslaved by TV as a human machine insofar as the television viewers are no longer consumers or users, nor even subjects who supposedly 'make' it, but intrinsic component pieces, 'input' and 'output', feedback or recurrences that are no longer connected to the machine in such a way as to produce or use it. $(2004,506)$

Deleuze and Guattari's example provides an important contribution to the analysis of the temporality of societies of metadata. This is so since metadata, like television, operates as an apparatus of both social subjection and machinic enslavement. On the one hand, societies of metadata turn every aspect of human activity (e.g. human attention) into a source of meta-information that is then processed and fed back into the productive sphere. On the other, societies of metadata reproduce individual time and individual desire as key elements for the reproduction of the economic cycle. In this sense, post-industrialism should not be understood simply as the substitution of machinic time for human time (and machinic labour for human labour). Instead, these two dimensions interact, constantly reinforcing each other. And it is precisely this twofold character, which demands a twofold understanding of its temporal character. Moreover, it could be argued that Guattari's concepts of human and machinic time presented above offer important insights into each one of these dimensions.

\footnotetext{
${ }^{4}$ Mauricio Lazzarato (2008) explains these two concepts by referring to Deleuze and Guattari's notions of molar and molecular arrangements: "We are enslaved to a machine when we are the cog in the wheels, one of the constituent parts enabling the machine to function. We are subjected to the machine when, constituted as its users, we are defined purely by the actions that use of the machine demands. Subjection operates at the molar level of the individuals (its social dimension, the roles, functions, representations and affections). Enslavement on the other hand operates at the molecular (or pre-individual or infra-social) level (affects, sensations, desires, those relationships not yet individuated or assigned to a subject)".

${ }^{5}$ I borrow this interpretation from Eugene Holland (1996). Holland writes: "in control society, disciplinary subjection is losing ground and making way for a perverse return to servitude [enslavement] as the prevailing mode of domination" (1996, 72). See also Deleuze (1995) and Lazzarato (2014).
} 


\section{Conclusion}

To conclude, it can be said that metadata is a technology of power that functions simultaneously at the levels of social subjection and machinic enslavement. Furthermore, each of these poles puts forth a specific temporality that can be defined using Guattari's distinction between human and machinic time.

It is useful to return to Berardi's account of the temporality of the attention economy in order to examine how human and machinic time articulate two temporal poles of societies of metadata. In terms of social subjection, on the one hand, it could be argued that metadata uses human attention in order to harvest meta-information about a specific user. In this sense, metadata does in fact oppose a human time of attention to an inhuman time of the flows of information. Furthermore, this entails a systematic normalisation of temporal experience and hence the ruin of our capacity to desire as reflexive individuals (Stiegler 2011, 58). At a subjective level, then, the current economic tendency to reduce the time between production and consumption dislocates the capacity of each individual to reflectively postpone the satisfaction of his or her desires. This creates a homogeneous state of cyber- or real-time in which individual temporal experience is constantly being overwhelmed by the endless acceleration of the economic field.

From the perspective of machinic enslavement, on the other hand, the subject appears as nothing more than a cog in a larger machine aimed at the reproduction of machinic surplus value. The user is an anonymous, pre-subjective source of data that allows the accumulation a broader object of power: metadata. Human attention becomes a machinic assemblage aimed at the extraction of meta-information that is fed back into the productive process in order to generate 'machinic surplus value' (Pasquinelli 2014, 15). Accordingly, human time is subsumed under machinic time. This means that human time no longer appears as the general equivalent of value, but instead connects with a series of other economic and social machines: the automated productive machine, the social machine of consumption, the desiringmachines captured by the advertising machine, etc. In this new productive context, capitalist exploitation of labour continues to ground the production of surplus value. Nevertheless, this does not take place through the seizure of a portion of labour-time from each individual worker, but through the appropriation of the whole social ensemble that grounds the production of machinic surplus value.

As in the example of television employed by Deleuze and Guattari (2004), metadata appears as a privileged object of analysis for understanding how machinic enslavement and social subjection can coexist in one and the same object, engaging with and resolving two necessary aspects of contemporary power formations. Moreover, human and machinic times can be used to conceptualise the temporal dimension of these two poles. From this perspective, it is possible to envisage the internal relation between metadata, the changes put forth by post-Fordism and the emerging power mechanisms of control societies.

\section{References}

Andrejevic, Mark. 2012. Estranged Free Labor. Digital Labor: The Internet as Playground and Factory, edited by Trebor Scholz. New York, London: Routledge.

Beller, Jonathan. 2006. The Cinematic Mode of Production: Attention Economy And the Society of the Spectacle. New Hampshire: University Press of New England.

Berardi Bifo, Franco. 2009. Precarious Rhapsody. London: Minor Compositions.

Berardi Bifo, Franco. 2011. Time, Acceleration, and Violence. e-Flux [Online]. Accessed March 16, 2014. http://www.e-flux.com/journal/time-acceleration-and-violence/.

Boyd, Danah and Kate Crawford. 2012. Critical Questions for Big Data: Provocations for a Cultural, Technological, and Scholarly Phenomenon. Information, Communication \& Society 15: 662-679.

Brynjolfsson, Erik and Andrew McAfee. 2012. Big Data: The Management Revolution. Harvard Bus Rev 90: 61-67.

Castells, Manuel. 2010. The Rise of the Network Society. Oxford: Wiley-Blackwell.

Crary, Jonathan. 2013. 24/7: Late Capitalism and the Ends of Sleep. New York: Verso.

Crogan, Patrick and Samuel Kinsley. 2012. Paying attention: Towards a Critique of the Attention Economy. Culture Machine 13: 1-29. 
Davenport, Thomas H. and John C. Beck. 2001. The Attention Economy: Understanding the New Currency of Business. Cambridge: Harvard Business School.

Deleuze, Giles. 1995. Postscript on Control Societies. In Negotiations: 1972-1990, edited by Giles Deleuze. New York: Columbia University Press.

Deleuze, Giles and Félix Guattari. 2004. A Thousand Plateaus. New York, London: Continuum.

Guattari, F élix . 2009. Capital as the Integral of Power Formations. In Soft Subversions, edited by S. Lotringer, 244-265. Los Angeles, CA: Semiotext(e).

Hardt, Michael. 1998. The Global Society of Control. Discourse, 139-152.

Hardt, Michael and Antonio Negri. 2000. Empire. New York: Harvard University Press.

Holland, Eugene W. 1998. From Schizophrenia to Social Control. In Deleuze \& Guattari: New Mappings in Politics, Philosophy, and Culture, edited by Eleanor Kaufman and Kevin J. Heller, 65-74. Minneapolis, MN, USA: University of Minnesota Press.

Harvey, David. 1989. The Condition of Postmodernity. Cambridge, Massachusetts Blackwell.

Jhally, Sut and Bill Livant. 1986. Watching as Working: The Valorization of Audience Consciousness. Journal of communication 36 (3): 124-143.

Lazzarato, Maurizio. 2008. The Machine. Transversal. Accessed March 16, 2015. http://eipcp.net/transversal/1106/lazzarato/en.

Lazzarato, Maurizio. 2014. Signs and Machines: Capitalism and the Production of Subjectivity. California: Semiotext(e).

Marazzi, Christian. 2008. Capital and language: From the New Economy to the War Economy. Los Angeles: Semiotext(e).

Manovich, Lev. 2012. Trending: the Promises and the Challenges of Big Social Data. In Debates in the Digital Humanities, edited by Matthew K. Gold. Minneapolis: University of Minnesota Press.

Marx, Karl. 1973. Grundrisse: Foundations of the Critique of Political Economy. New York: Random House.

Negri, Antonio. 1996. Twenty Theses on Marx. In Marxism Beyond Marxism, edited by Saree Makdisi, Cesare Cararino and Rebecca E. Karl. New York: Routledge.

Negri, Antonio and Hardt, Michael. 1999. Value and Affect. Boundary 26 (2): 77-88.

Pasquinelli, Matteo. 2014. Italian Operaismo and the Information Machine. Theory, Culture \& Society 31 (4).

Postone, Moishe. 1993. Time, Labor, and Social Domination: A Reinterpretation of Marx's Critical Theory. Cambridge: Cambridge University Press.

Raunig, Gerald. 2008. A Few Fragments on Machines. Transversal. Accessed March 16, 2015. http://eipcp.net/transversal/1106/raunig/en.

Simon, Herbert A. 1969. Designing Organizations for an Information-Rich World. Zeus. Accessed March 16, 2015. http://zeus.zeit.de/2007/39/simon.pdf.

Stiegler, Bernard. 2011. Suffocated Desire or How the Cultural Industry Destroys the Individual: Contribution to a Theory of Mass Consumption. Parrhesia 13: 52-61.

Terranova, Tiziana. 2004. Network Culture: Politics for the Information Age. London: Pluto Press.

Virilio, Paul. 1991. The Aesthetics of Disappearance. New York: Semiotext.

Virilio, Paul. 1995. Speed and Information: Cyberspace Alarm. CTHEORY. Accessed March 16, 2015. http://www.ctheory.net/articles.aspx?id=72.

Virilio, Paul. 2006. Speed and Politics. Los Angeles: Semiotext.

\section{About the Author}

Claudio Celis

Claudio Celis is a PhD candidate awaiting his viva exam in Critical and Cultural Theory at Cardiff University. His research focuses on the relation between technology, labour and power in contemporary capitalism. In particular, he interrogates the validity of Marx's critique of political economy for a postindustrial context. 